\title{
Business Process Reengineering as the Current Best Methodology for Improving the Business Process
}

\author{
Zuraida Zaini ${ }^{1}$, Aslina Saad ${ }^{2}$ \\ ${ }^{1}$ Faculty of Arts, Computing \& Creative Industry, UPSI; m20122002003@siswa.upsi.edu.my \\ ${ }^{2}$ Faculty of Arts, Computing \& Creative Industry,UPSI; aslina@fskik.upsi.edu.my
}

https://doi.org/10.37134/jictie.vol6.7.2019

\begin{abstract}
Currently, most companies or organizations can select a number of methodologies to improve their business processes, which include Six Sigma, Lean Thinking, Lean Six Sigma, Business Process Reengineering, Total Quality Management, Kaizen and Poka-Yoka. However, selecting an appropriate methodology has to be guided by the organization's objectives. In this respect, the BPR is one of the best methodologies that can help organizations to ensure the continuity of their businesses so they will remain relevant for a long time. More importantly, the BPR can help members of organizations to rethink about their existing practices such as to introduce significant improvements to their business process. Based on a literature review, the researchers carried out a comparative analysis on four leading methodologies, namely BPR, Six Sigma, Lean Thinking, and Kaizen. The comparison of the methodologies were based on 11 aspects, namely the concept, effect, use of information technology, focus, involvement of workers, degree of change, level of risk, creation of a study, model, duration, and cost. In addition, the researchers elaborated the six phases of the implementation of BPR. The comparative analysis revealed that the BPR was the best among the four methodologies analysed, as it could help radically and holistically improve the overall business process of an organization. Thus, organizations that need such a change in their business processes can adopt the BPR as the most appropriate methodology than can help bring the intended improvements to their workplace.
\end{abstract}

Keywords: Business Process Reengineering (BPR), business process, methodology, comparisons.

\section{INTRODUCTION}

The value adding process is vital to ensure the continuity of an organization to remain relevant with the passing of time. With each passing era, business environments too change that naturally would have serious repercussions on the organizations' business dealings in keeping abreast with prevailing demands. Arguably, such a change helps an organization to improve its strategy and methodology such as to be successful in the business realm. In choosing a methodology, organization has to consider various aspects that are suitable for its business process, such as the level of business risks, duration, individuals involved, and investment cost. Such consideration will ensure that the intended change will proceed smoothly on the path and be perfected to achieve the intended goals. Based on this study, the 
researchers was able to examine and compare a number of methodologies practiced in organizations, which revealed that BPR is the most effective methodology to date. Such revelation is hardly surprising given that it always emphasizes critical changes that are taking place, such as cost saving and reduced time. In addition, the usefulness of BPR is further enhanced by the use of information technology (IT).

\section{Contemporary Methodologies of Business Strategies}

Clearly, the implementation of any business process improvement methodology in any field brings several benefits and create many opportunities to improve the competitiveness among business organizations. Nevertheless, the accuracy in choosing such a methodology takes priority above all things, as it will increase the probability of attaining success. Of course, each methodology has its own attributes that are different from others that are governed by a number of factors, such as the purpose, level, scope, and focus of the intended change, which collectively needs to be taken into account. In this respect, Sturdy (2010) asserts that change management is an essential requirement that helps facilitate the infusion of a newly designed process and structure into the current working practice and deal with any oppositions that resist such a change. In this paper, the researchers have discussed four methodologies, namely BPR, Six Sigma, Lean Thinking, and Kaizen in detail such as to determine the most appropriate for the business process.

\section{THE SIGNIFICANCE USE OF IT IN BUSINESS PROCESS REENGINEERING (BPR)}

Any organization that has implemented BPR can be identified by the drastic improvements occurring in its business. Goksoy et al. (2011) state that BPR will continue to remain as the popular tool for the management of change for the many decades to come. Its appeal as a potent tool owes to the following characteristics:

- It emphasises innovation and improvements.

- It involves the process of redesigning.

- It utilizes IT, which is an important ingredient of BPR and a basic component in today's business activities.

- It helps reduce cost and improve quality of service.

Obviously, IT is an indispensable tool in the redesigning the business process. In particular, IT can support a new business process or redesign such a process for further improvements. Additionally, IT plays an important role in BPR as it can effectively help to automate manual process through automation. It also helps business to run at various locations and provides better services for customers through fast, paperless transactions.

As such, Sudhakar (2010) contends that it is important for any business organization to have IT experts to help the implementation of BPR, as technology can help reduce the time cycle in fulfilling 
customer's requests. The following are the benefits offered by IT when integrated into the BPR process:

1 Reduction of cycle time.

2 Elimination of fraudulent practices.

3 Elimination of corruption.

4 Improved accuracy and security of business transactions.

5 Increased working efficiency.

6 Improved quality of work, services, or products.

7 Fast communication between clients and personnel.

8 Better progress tracking.

Goksoy et al. (2011) have agreed with Hammer (1990) that IT as the main factor that enables BPR to introduce changes more radically compared to other methodologies. Likewise, Davenport and Short (1998) affirm such an important role played by IT by stating that it helps organisations to carry out changes through re-engineering such that IT can viewed as the catalyst of BPR. As such, IT has become one of the important tools in redesigning of businesses. In fact, IT and BPR share a recursive relation that helps practitioners to take the next appropriate steps. Muhammad Aizat and Mohd. Rizal Razalli (2015) strongly agreed that IT infrastructure is a must for organizations to develop innovation. Without proper management of IT infrastructure, BPR initiatives of any organizations would likely to be failed.

According to Dragan and Toni (2017) IT provides new advantages to business operations and can be used as a tool for business process transformation that crosses several functional lines. IT mechanism can be used to reduce the organizational complexity and enable wider organizational change. Still, in order to have real improvements the change has to be performed by people who know the objective and know how to use the IT tools to achieve it. Norlena, Kabiru and Mohd Rizal Razalli (2017) also agreed that IT has always become as a critical tool for the execution of business strategy and a driver of business performance. With rapid changes in particular to the financial markets, IT capability seems to be the backbone to improve the business processes.

\section{LITERATURE REVIEW}

\section{Business Process}

Widigdo et al. (2016) was stated that business process is a collection of related structured activities in order to solve a specific problem or to produce service or product. It consists of a series of logically related entities that makes use of organizational resources. Islam and Ahmed (2012) have showed the other view of business process. According to them, Hammer and Champy (1993) was defined business process as "collective activities that take in one or more inputs and generate an output of a certain value for the clients". In addition, Cook (1995) states that a business process is a series of steps of 
business activities, of which its main aim is to satisfy customers by focusing on what they needed, when they needed it, and how they used it. Thus, the improvement process can be used to help address the above needs. Essentially, this process is a method that helps design and manage a set of business activities. Furthermore, Liem (2005) adds further refinements to the above notion by stating that a business process is a set of related activities that has to be implemented based on a number of rules to achieve the intended business objectives.

In contrast, Radhakrishnan et al. (2010) emphasises a business process as the unique way in which an organization carries out its tasks. In addition, he states that, based on the opinions of business process experts, a business process essentially consists of two main characteristics, namely the involvement of customers and a boundary that transcends the organizations. He also argues that a business process performs a set of activities that changes an input into an output (i.e., goods or services). Alternatively, this process can also viewed as a process that involves people and tools as the mediator. Figure 1 shows such development of a business process as conceptualized by Radhakrishnan et al. (2010).

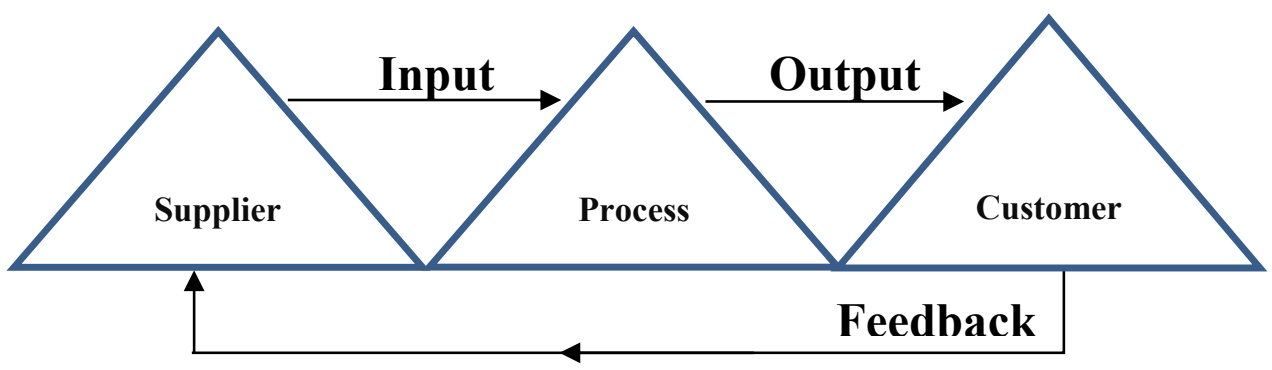

Figure 1: The Business Process

(Radhakrishnan et al., 2010: Business Process Reengineering, Text and Cases)

Anandayah (2011) concurs with the above notion by offering his own definition that a business process is an activity that changes a set of inputs into an output in the form of goods or services for users with the use of man and machine. Similarly, Solaimurugan (2011) defined the business process as an activity or a process using both people and tools to change a set of inputs into an output in the form of goods or services. In agreement with above definitions, Milan et al. (2014) assert that the business process is a set of essential activities that is sufficient for transforming an input (sources) into a manufactured value (product or end service) to meet users' or organisations' needs.

Hong et al. (2016) have agreed with Martinsons (2004) by argued that cultural, economic and political aspects need to be considered in altering business processes, and corporate culture is the most important factor, especially in the case of Asian countries. BPR pushes for radical change in business processes, which may lead to an adverse reaction from employees who are familiar with conventional 
business processes. While Bhaskar (2018) says that almost all companies are built around four key core business processes upon which the ultimate success of the company depends in providing quality product or service leading to survival and growth. These four core processes are the following:

1 The product or service development process: Conception, design, and launch of new products or services to customers.

2 The order-generation process: The process of attracting and securing customers and activities meant to interpret and track requests for products or services from the customers.

3 The order-fulfilment process: Creation, preparation, and delivery of the order to the customer.

4 The customer-service process: Activities designed to sustain customer satisfaction after delivery of an order.

The four processes may look different from industry to industry, and even from company to company within industry. In fact, one can ask where these processes are in some industries. But they are present in one guise or another, and they are the processes upon which a company focuses the most attention.

\section{Business Process Reengineering (BPR)}

Changes are important to every organization to sustain the continuity of its services or business such as to remain relevant for many years to come. BPR was introduced by Hammer (1993) as a radical rethinking and redesigning of business process that helps achieve drastic improvements in a critical situation and important performance measures, such as cost, quality, services, and promptness; by contrast, Davenport (1993) views BPR as an innovation process. According to Sturdy (2010), Davenport has study on redesign processes of several organizations and indicates that methods practiced in such business entities are critical to the success of an innovation project.

In consistent with Sturdy's (2010) contention, Banham (2010) (cited in Sungau et al., 2013) argues that organizations need to undergo a continuous change to be tandem with the changes in technology and in customers' demands. Patwardhan et al.'s (2008) definition adds credence to the above assertion, arguing that BPR is a management approach of rethinking of existing activities, processes, and other related aspects of a business. Likewise, Hanafizadeh and Ossouli, (2011) contend that BPR is a basis for radical rethinking and redesigning of business process to help attain clear improvements in cost, quality, services, and timing. Their contention is consistent with Khodambashi's (2013), who states that BPR is an attempt to improve process efficiency using a radical approach that helps change or eliminate activities that do not add values and to rebuild the process, structure, and culture of a company. Gathari and Shamsi (2014) insists that the objective of BPR is not only to improve cost and performance, but also to meld organisational cultures and impose parental controls on the acquired business. Mergers offer a tremendous opportunity to improve efficiency and reduce operating costs through consolidation of activities, streamlining of operations, and integration of business processes. In line with the others authors, Norlena et al. (2017) had found BPR does not seek to alter or fix existing 
processes, but forces companies to ask whether or not a process is necessary, and then seeks to find a better way to do it. BPR integrates all departments into a complete process that has been designed to fulfil a specific business goal. Hence, successful implementation of BPR enables organizations to achieve dramatic gains in business performance.

Clearly, the above definitions and assertions suggest that BPR is a process that can help solve a range of business problems to date. Moreover, it serves as an important methodology to introduce changes in large corporate organisations. Using this methodology, aspects related to the business process can be analysed, made easier, and redesigned. This is hardly surprising as BPR involves rethinking of all business processes that are used to radically reduce the cost of making products or providing services. Since 1990, BPR has been acknowledged as a bold business management strategy that helps an organisation to analyse its workflows and processes. Equally important, BPR also plays a vital role in helping organisations to rethink the daily activities carried out in ways to improve customer services, reduce operational cost, and become a first-class competitor.

According to Habib et al. (2013), in the period of organizational changes, a majority of the business focuses centre on aspects related to efforts in bringing changes to the structure, processes, policies, and procedures of companies, which would have a profound impact on workers, systems, processes, and work culture in some parts of an organization or throughout the organization. To accept such changes and to face potential challenges, it is important to identify exactly the change that is needed and to foresee the extent to which such a change can have an impact. As such, it is essential to determine the type of change and available tools that can help implement the required change.

Previous studies indicate that the most common BPR methodology used in many business processes is Hammer and Champy's methodology. Nevertheless, recent developments show that Davenport's methodology is becoming more prevalent given its emphasis on the use of IT as the main driver of change. Moreover, several scholars, such as Aslina (2005), have cautioned that the use of BPR should not be generalized to all business situations, as each type of businesses has its own unanticipated elements of surprise. Patwardhan et al. (2008) also concurs with the above caution, stating that the approach to identify relevant sub-processes deemed suitable for BPR involves a "door-to-door" mapping process that helps improve its utility. Furthermore, such an approach can help organisations to identify high-value activities and poorly performing activities. In particular, the latter activities can be measured and analysed to determine their negative impacts and methods of disposal. 


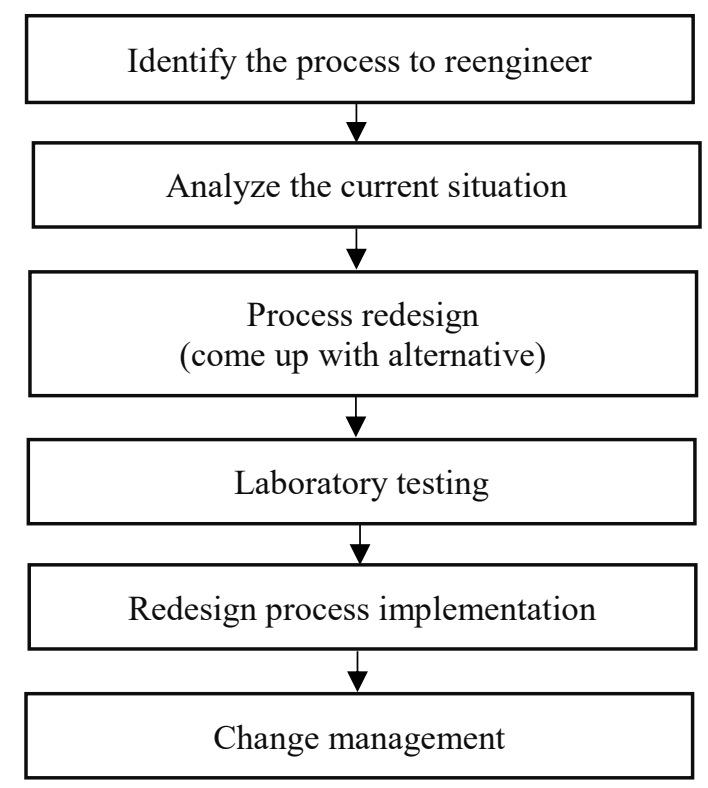

Figure 2: The Six Steps of BPR (Sudhakar., 2010)

According to Sudhakar (2010), practitioners need to identify the internal process of their company that is required to be redesigned. Using BPR, such process can be effectively redesigned to help the company to achieve better profits, cost reduction, quality, and services. Hence, the company has to implement BPR according to the recommended steps as shown in Figure 2.0. Bahramnejad et al. (2015) also shares a similar view, arguing that BPR can improve the chances of an organization to be resilient and strong in a highly competitive business. Nonetheless, the number of companies that managed to stay relevant are miserably low, with many having to quit their business, thus lies the urgent need for a new methodology to help minimise such a poor success rate. Such a methodology can use the six steps recommended by Davenport, but such steps have to be perfectly aligned with the change desired by an organization. Figure 2 shows all the six steps recommended by Davenport (1993).

Step 1: Identify the vision and aims

This step focuses on all follow-up actions based on a company's vision and target process. In this regard, Davenport (1993) cautions that in addition to cost reduction, worker satisfaction, reduction in production time, and performance enhancement should also be prioritised.

Step 2: Identify the business process

This step helps identify business processes that need to be redesigned. Thus, according to Davenport (1993), the BPR team has to direct attention on several important core processes. 


\section{Step 3: Understand and Assess the Process}

This step needs to assess the accurate functions and performance of the selected business process. In fact, this step essentially to differentiate this methodology with Hammer's methodology. Specifically, when redesigning the process, previous practices should not be replicated and a new benchmark for the redesigned process should be established.

\section{Step 4: Information Technology}

The aim of this step is to study the suitability of the use of IT hardware and software for the newly designed work process.

\section{Step 5: Prototyping Process}

This step encompasses the functions of prototype design that match the newly designed business process.

\section{Step 6: Implementation}

In this final step, the prototype will be tested throughout the organization prior to its implementation. Notably, this step is the most important step of all to ensure the success of the BPR of the organization.

\section{Lean Thinking}

Lean Thinking is a concept introduced by James Womack and Daniel Jones in their study in the late 80s. In their study, they thoroughly discuss the success of Toyota Motor Company that uses an innovative system called Lean Production. With this manufacturing system, this company managed to improve its business process, far surpassing its two main rivals, namely Ford and General Motors. Womack et al. (1990) (cited in Hagg et al., 2007) refer Lean as a method to identify values, make a list of such values, plan the best sequence of actions based on the list, and carry out such actions without any interference. As such, this method helps eliminate wastes, which is not needed in producing a product or a service. Given its huge impact on manufacturing practices, Hagg et al. (2007) added Lean has now been widely applied to many other fields as well. While Lawal (2014) was said, from the cognitive perspective, Smith (2012) and Campbell (2007) state that Lean is the basis with which an organization can help nurture thinking and assessing skills that leads to continuous changes in the organization's work culture.

As highlighted in their book, Hagg et al. (2007) state that for an organisation to use Lean, its top management must nurture a new philosophy regarding Lean to ensure its implementation will be a success. Lean is concerns with not only "a set of tools" but a new approach for routine business process. Similar with other management strategies, Lean too has its own method of implementation, which consists of five steps as follows: 


\begin{abstract}
Step $1 \quad$ Identify values that are highly required by clients.
Step 2 Identify the flow of values, which consists of steps to quantify such values. In this phase, each step will be examined to eliminate wastes, errors, bureaucracy, and redundant steps.

Step 3 Create the flow of values without any elements of wastes or unwanted excesses.

Step $4 \quad$ Perform manufacturing according to the choices made by the customers.

Step 5 Continue working for perception through systematic work by focussing on what has been done, who has performed it, and what has been done with it.
\end{abstract}

Additionally, Maryati et al. (2012) assert that Lean is effective in solving chronic problems, because it uses number of tools, such as Value Stream Mapping (VSM) and A3, that help solve such problems with better precision. They also contend that VSM can be used as a method to provide an overall picture and understanding of the management with regard to problem solving using the A3 report in more detail.

\title{
Six Sigma
}

Six Sigma is defined as a set of tools or strategies to minimize errors and variance in the business process by emphasizing on the process of holistic improvement. According to Hayler and Nicholas (2007) (cited in Gershon, 2010), Six Sigma was first introduced by Motorola in the US IN 1985 as a model of manufacturing process, which was then made popular by the Chief Executive Officer of General Electric, Jack Welch, in the same year. Hayler and Nicholas (2007) state that Six Sigma is a very potent approach for improving business processes of manufacturing, services, and industrial transactions. As such, they defined Six Sigma as a scientific management approach of infusion by combining various creative and technical methods of change management, tools and techniques to help improve the business process.

On the other hand, Pande (2000) states that Six Sigma is a system that is comprehensive and flexible to help achieve, maintain, and maximise the success of a business. In addition, Pyzdek (2003) (cited in Gershon, 2010) defined Six Sigma as a strict, focused, and effective implementation of proven techniques and quality principles. The philosophy of Six Sigma is that a sound understanding of the importance of reducing differences can help solve many business problems. With the use of a statistical tool, the management team will be able to analyse fluctuating processes that can help them predict the required decisions from such processes. If the results are unsatisfactory, other related tools will be used to better understand the elements that influence such processes. As such, Six Sigma, as illustrates in Figure 3, helps practitioners to focus on improving the business process by eliminating any potential sources of variance. 


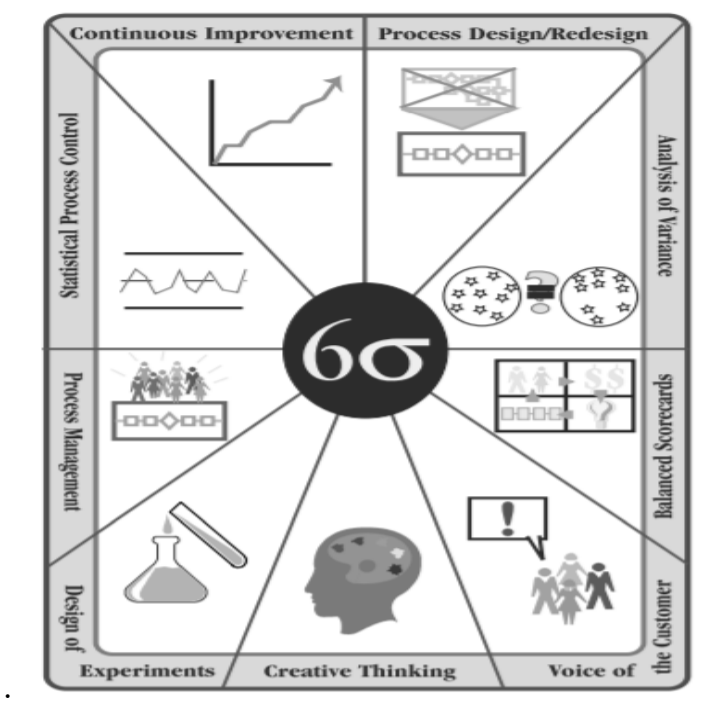

Figure 3: The Method and Tools of Six Sigma (Pande et.al., 2000)

The methodology used in Six Sigma is DMAIC, which stands for Define, Measure, Analyse, Improve, and Control. Four types of tools are commonly used with Six Sigma, namely the analytical tools, management program tools, data collection tools, and online projects tool for global and local teams (DMAIC). The followings are the steps of DMAIC:

\section{Step 1: Define}

This is a very challenging step for the team, entailing each team member to ask the following questions to help brainstorm the problems.

- What is currently being done?

- Why do we need to solve this problem?

- Who are the clients?

- What are the clients' needs?

- How is the work being performed?

- What are the benefits of improvements?

\section{Step 2: Measure}

This step has two main objectives as follows:

- To collect data that help validate and measure the problems and to determine opportunities that can be gained from solving such problems.

- To create numerical indicator for the sources of the problems. 


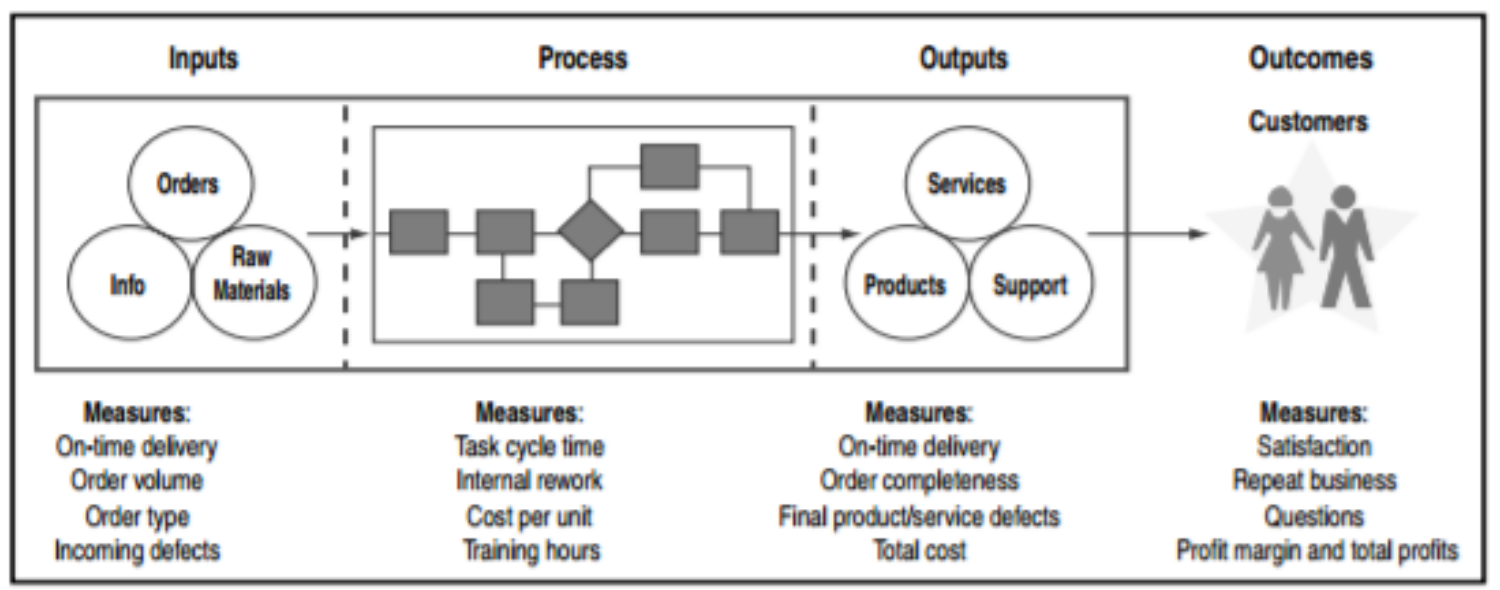

Figure 4: The type of inputs, processes, outputs and outcomes of DMAIC

\section{Step 3: Analysis}

In this step, the team will identify the details of the processes to help gain a firm understanding of the prevailing problems.

\section{Step 4: Improve}

In this step, the team will perform the required actions to solve the problems. In addition, the team can alter the scope of their project based on their improved understanding of the problems and processes. Once the objectives are set, the process of planning to achieve the aims will be conducted.

\section{Step 5: Control}

The main objective of this control step is to prevent the organisation from repeating its old practices and processes. The control step is specifically performed to do the following:

- To develop a monitoring process to detect changes that have been determined.

- To prepare an action plan to overcome any potential problems.

- To help the management team to focus on critical measurements by providing them with the latest information regarding the outcomes $(\mathrm{Y})$ of the project and the main process measurement $(\mathrm{X})$.

Additionally, Six Sigma has another vital tool, namely DMADV, which stands for Define, Measure, Analyse, Design, and And Verify. While DMAIC is used to improve or to upgrade a project that failed to meet users' needs, DMADV is an enhanced system that can help develop a new project that fulfil users' needs and the objectives of the project. 
Aquila (2017) have stated that Six Sigma became popular with organizational leaders because of its ability to provide for better quality products that cost less to make and its connection with helping an organization to achieve a sustainable competitive advantage. Because organizational leaders experienced a sustainable competitive advantage when they used Six Sigma, industry leaders outside of manufacturing adapted and altered as needed Six Sigma' s methodology for their purposes.

\section{Kaizen}

This methodology is developed by Training Within Industry (TWI) after the Second World War. This methodology has helped many organizations, and it is still being used to this day. According to Anwar et al. (2013), the term "Kaizen" means a positive change that encourages an individual to start with a small step in carrying out efforts for improvement of things considered negative. Specifically, "Kai' means a change or an action to change, whilst "Zen" means good. In practical terms, Kaizen is known as Ringgi, which is a system that involves all workers, from the top management to general workers of an organization. Using such a system, each activity will be performed continuously and every worker is encouraged to suggest any ideas to improve the business process no matter how small they are.

Additionally, he argues that Kaizen cannot be separated from the components that serve as the backbone of the improvement process, as they help ensure the activities of Kaizen can be carried out smoothly according to the suitability of the intended process. This system has a number of important, namely Plan, Do, Check, Act (PDCA), Total Quality Management (TQM), Five S (5S), Total Productive Maintenance (TPM), Just In Time (JIT), Horenso, Five Why (5W), Mieruka and Genchi Genbutsu. He also states that, based on the Kaizen model, an existing process will deteriorate if the required continuous improvements are not carried out, incurring a huge cost to improve it later. This system emphasizes small, incremental improvements that will lead to profound outcomes in the long term. Hence, this system uses a low-risk approach, but it will certainly deliver positive outcomes on a gradual basis.

In addition, he asserts that Kaizen does not encourage drastic changes, but it focusses on persistent commitment and meticulous preparations to continuously seek small ideas for improvements. Furthermore, Kaizen must be abandoned when an objective is met, as it is a never-ending process that is needed to produce something new that will always be better than its predecessors. In this regard, Imai (1986) (cited in Remy, 2011) instates that Kaizen has its own philosophy. It is a set of ongoing improvements involving everyone, including both managers and workers. The kaizen philosophy assumes that "our way of life [...] deserves to be constantly improved". Kaizen means continuous improvements and Kairo that refers to process improvement. The methodology of Kaizen can be described as follows:

- First, all workers of the organization are involved in the change process.

- Second, improvements are made to methods or processes. 
- Third, changes are carried out continuously and gradually.

- Forth, the team is the main enabler or driver that carries out the efforts for change.

While Puneet Sharma et al. (2015), was elaborated Kaizen is a concept that focuses on improving a work area or an organization in incremental steps by eliminating waste. Kaizen can be applied to any area in need of improvement. Industries especially manufacturing is currently faced with the conflicting pressure to improving customer satisfaction and service as well as pressures of cost reduction, reducing lead time, and quality improvement in order to get better results.

\section{The Implementation Phase of Kaizen}

Puvanasvaran et al. (2010) have explained in order to implement Kaizen, there are seven step to be followed. The steps are as follows:

Step 1: Define Pilot Area

Define pilot area is the first step towards ongoing with the improvement activities. Bottleneck processes are commonly defined the pilot area.

\section{Step 2: Identify Losses}

Basically, losses are identified from abnormality. In this project, we choose to focus on total loss of time. This is the problem that we observed in the line. Other losses are not visible. This is because the company is project type based. So, times are most significant due to on time delivery mission. In order to identify the time losses, time of each step in process mapping of production processes are categorize to Value Added (VA) and Non Value Added (NVA).

\section{Step 3: Plan Preparation}

Scheduling the project on the agreed time frame. Step by step of kaizen must be followed to get the actual result of kaizen steps effectiveness. Each steps or activities is perfectly allocated its duration.

\section{Step 4: Organizing Team}

The next step in Kaizen will be organizing the Project Team. The team are put together and expected to come up with a solution to a problem and success in the project conducted. Target is set due to project planning and project schedule.

\section{Step 5: Project Implementation}

At this step, Plan, Do, Check and Act Cycle (PDCA) was used as problem solving approach. Problems are solved more effectively when used the systematic approach. In PDCA approach, there have seven steps that need to follow. Step by step was followed without skip. 
1 Define the problem

2 Detect root cause

3 Data collection

4 Analyse and establish solution for the problem

5 Implement solutions

6 Check and monitor results

7 Standardize solutions

\section{Step 6: Conform Effectiveness}

In this step, the effectiveness of kaizen steps and problem solving approach is defined by using comparisons between before and after implementation. Time taken with the project conducted without rework or redesign part

\section{Step 7: Follow Up}

In this section, in order to make sure the processes are operating at normal condition even after implementations, some actions have been taken. The actions taken will provide stability and reliability to the improvements that have been carried out. Puvanasvaran et al. (2010) have specified three main actions that can be taken to avoid the problems from recurrence happening. The actions are based on brainstorming among members and also discussion among the workers itself. The actions taken are as follows:

1 Check sheet. The list contains the important steps that must be follows without skipping. The check sheet will be move together with processing flow processes. Each process that has been done must mark at the check sheet as token had elapsed that process. This item is necessary to be added in this step because it acts as a guideline to prevent any skipping due to human error.

2 Workers involvement. One of the essential aspects in preventing previous false to happen again is by cooperation from co- workers. Workers are highly responsible for the task given. The time spent for processing the sales order and the level of workers involvement in the process are crucial for contributing on time delivery and increasing the customer satisfaction. An employee is responsible to follow the correct work sequences and ethics.

3 Top management strict enforcement. Enforcing the right work attitude is necessary for the positive outcome from the improvements done. Top management staffs must co- operate and enforce the law and ensure the workers are performing the work as in the instruction manual. Fine or equivalent terms of punishment should be imposed for errant workers. 


\section{Differences among the Four Processes of the Improvement Strategies}

As discussed, the differences among the four processes of the improvement strategies can be categorised into 11 aspects. Understanding such differences is important to help organizations or individuals to adopt and amend such processes that are suitable for solving their particular problems. Matching the two aspects (between processes and problems) will lead to better selection of relevant methodology that can be consistently applied to achieve the intended goals. Table 1 summarizes such differences among the four processes of the improvement strategies.

Table 1: The differences among BPR, Lean, Six Sigma, and Kaizen

\begin{tabular}{|c|c|c|c|c|}
\hline $\begin{array}{l}\text { Type of Methodology / } \\
\text { Characteristics }\end{array}$ & Bpr & Lean & Six Sigma & Kaizen \\
\hline 1) Definition / Aim /Concept & $\begin{array}{l}\text { Redesign the } \\
\text { business process with } \\
\text { the aim to improve } \\
\text { efficiency and } \\
\text { effectiveness, such as } \\
\text { to reduce cost and } \\
\text { production time and } \\
\text { to improve quality. }\end{array}$ & $\begin{array}{l}\text { Improve process by } \\
\text { eliminating unwanted } \\
\text { activities. }\end{array}$ & Reduce variance & $\begin{array}{l}\text { Carry out small, } \\
\text { incremental changes } \\
\text { that do not require } \\
\text { the use of } \\
\text { technology. }\end{array}$ \\
\hline 2) Effect & $\begin{array}{l}\text { Changes in existing } \\
\text { processes. }\end{array}$ & $\begin{array}{l}\text { Reduction in of } \\
\text { workflow time. }\end{array}$ & $\begin{array}{l}\text { Standardisation of } \\
\text { processes. }\end{array}$ & $\begin{array}{l}\text { Continuous } \\
\text { improvements. }\end{array}$ \\
\hline 3) Phase / technique & $\begin{array}{l}\text { i. Set the vision and } \\
\text { objectives of the } \\
\text { processes. } \\
\text { ii. Identify processes } \\
\text { requiring redesign. } \\
\text { iii. Understand and } \\
\text { analyse the As It } \\
\text { Processes. } \\
\text { iv. Identify the use of } \\
\text { IT. } \\
\text { v. Develop the } \\
\text { prototype processes. } \\
\text { vi. Implement the } \\
\text { redesigned processes. }\end{array}$ & $\begin{array}{l}\text { i.Identify values. } \\
\text { ii.Identify flow of } \\
\text { values. } \\
\text { iii.Develop the flow } \\
\text { of values. } \\
\text { iv.Carry out } \\
\text { production based } \\
\text { on customers' } \\
\text { choices. } \\
\text { v.Continue to } \\
\text { achieve perfection } \\
\text { and use the Value } \\
\text { Stream Mapping } \\
\text { (VSM) and A3 } \\
\text { Report. }\end{array}$ & $\begin{array}{l}\text { (DMAIC) } \\
\text { i. Identify } \\
\text { ii. Measure } \\
\text { iii. Analyse } \\
\text { iv. Improve } \\
\text { v. Control } \\
\text { and } \\
\\
\text { (DMADV) } \\
\text { i. Identify } \\
\text { ii. Measure } \\
\text { iii. Analyse } \\
\text { iv. Design } \\
\text { v. Validate }\end{array}$ & $\begin{array}{l}\text { i. Involvement of all } \\
\text { workers. } \\
\text { ii. Improve the } \\
\text { methods or } \\
\text { processes. } \\
\text { iii. Small, } \\
\text { incremental } \\
\text { improvement. } \\
\text { iv. Set up a team as } \\
\text { the driver for change } \\
\text { and success. }\end{array}$ \\
\hline 4) Use of Information Technology & Main enabler. & Main enabler. & Main enabler. & None. \\
\hline 5) Focus & $\begin{array}{l}\text { Changes from start to } \\
\text { finish. }\end{array}$ & $\begin{array}{l}\text { Identify and } \\
\text { eliminate processes } \\
\text { of no added value. }\end{array}$ & $\begin{array}{l}\text { Improve the current } \\
\text { process. }\end{array}$ & $\begin{array}{l}\text { Continuous } \\
\text { improvement. }\end{array}$ \\
\hline 6) Involvement of staff & From top to bottom. & From top to bottom. & From top to bottom. & All the stakeholders. \\
\hline
\end{tabular}




\begin{tabular}{lllll}
\hline $\begin{array}{l}\text { Type of Methodology / } \\
\text { Characteristics }\end{array}$ & \multicolumn{1}{c}{ Bpr } & Lean & Six Sigma & Kaizen \\
\hline 7) Degree of change & Radical. & Fast. & Incrementral. & Slow. \\
\hline 8) Level of risk & High. & Moderate. & Moderate. & None. \\
\hline 9) Outcome of study model & Not available. & Available. & Available. & Not available. \\
\hline 10) Duration & 6 months and above. & $\begin{array}{l}\text { Dependent on the } \\
\text { process. }\end{array}$ & 4 months. & Depend time. \\
\hline 11) Cost incurred & Yes. & Yes. & Yes. & No. \\
\hline
\end{tabular}

\section{ANALYSIS ON THE DIFFERENT ATTRIBUTES OF THE EXISTING METHODOLOGIES}

Table 1 summarizes the strengths and weaknesses of the methodologies. For example, BPR has the concept of redesigning the business process to improve efficiency and effectiveness such as to save time and cost and to increase quality. It focuses on reducing time and cost of processes as opposed to that of the Kaizen concept. Whereas, Kaizen is a change concept that is slow to materialise because it is carried out incrementally on a small scale.

From the conceptual perspective, BPR focuses on existing processes that may have to be examined to detect any inefficient elements and refined to create new processes that improve the overall process of the organization. In contrast, Kaizen is a concept that focuses on making improvements on a continuous basis, meaning any weaknesses in the business process will be dealt with continuously until they are completely solved and the aims of the organization are met. Clearly, this shows that changes made are not focused on any specific processes, but they are performed continuously until all weaknesses are eliminated. Furthermore, BPR needs six months and more to complete its process. Such is not the case for Kaizen, which does not have any prescribed time frame.

From the aspect of cost, BPR seems more expensive given that it incurs high cost in redesigning the business process and in producing dedicated systems. This is in stark contrast to Kaizen that involves relatively inexpensive changes but still able improve productivity, quality, and revenues. Nevertheless, both share a similar trait, as they do not require a study model for the improvement process being carried out.

Similarly, there are differences between Six Sigma and Lean. In principle, both have the same main objective, which is to eliminate wastes and to create an efficient system. Nonetheless, their main difference lies in the technique used to identify wastes. Practitioners of Lean believe that existing wastes are the result of steps that have no positive values, whereas practitioners of Six Sigma argues that wastes in the production are caused by a variety of processes. In addition, Six Sigma has two main methods, namely DMAIC and DMADV. The former is used to identify any waste of the As Is Process. Whereas, the latter is used to develop a new process that capable of achieving the aims of the organization. Evidently, the use of these two tools entails the organization to determine the required change as either to create a new business process or to introduce change to the As Is Process. Admittedly, any mistakes made in using such tools can result in a waste of time and different outcomes. 
Similarly, Lean to has its own tools to detect any weakness in the process, namely the Value Stream Mapping and A3 Report. However, to use these tools, it requires active involvement of all parties to think about the problems and to propose a number of practical solutions to the problems.

\section{BUSINESS PROCESS REENGINEERING (BPR) AS THE CURRENT BEST METHODOLOGY}

The comparison among the inherent strengths and weaknesses of four methodologies revealed that BPR has a slight advantage over the other three methodologies. Specifically, BPR has the capability to introduce a profound overall change to an organization as it involves all aspects of a business by analysing, streamlining, and redesigning existing problematic or weak processes. Furthermore, from the philosophical standpoint, BPR involves rethinking of the business process that can help drastically reduce the cost of products or services.

From the historical perspective, BPR has been accepted as a powerful business management strategy since 1990. This is hardly surprising given its focus on the analysis and workflow of the business process practiced by an organization. Over the years, it has been very influential in helping organizations to rethink the daily, routine works that can be further improved such as to introduce profound effects on customer services, notably on saving time, reducing operational cost, and becoming a world-class competitor.

To achieve such improvements, Sungau et al. (2013) have agreed with Slack et al., (2007) by argued that organizations need to redesign their business processes. To this end, a number of techniques have been used to create new business processes that are appropriate with the current business environment, thus enabling the organizations to improve their performance. Invariably, as highlighted by Sudhakar (2010), many organizations have been using IT as an indispensable tool to reduce the cycle time in fulfilling customers' needs. In addition, IT helps reduce fraudulent and corrupt practices, and it helps to improve the accuracy and security of information. More importantly, IT enables fast communication that help improve the quality of work, services, and products.

Conventional way has viewed IT as an automated force rather than an advanced method to reshape their business in modern era. The examination of IT will reveal the use of IT tools within the BPR process which typically results in faster, better and cheaper solutions at each phase of the BPR process. Natasha (2003) stated that the understanding of IT is a compulsory before selecting BPR as business improvement method of any organisation. Failed to understand and aligned the use of IT can lead to the failure of implementing BPR as available resources might be wasted. Wide knowledge in IT is a vital factor for BPR implementation because it manages to shorten time taken in completing task or process. Public knows that IT consists of two main components, hardware and software. Good hardware is important to support the software being used. However, in todays' world with a new wave, IT role has become more than that.

Current trend called as big data has changed the way of reducing process and choosing task to be diminished, added or retained. Andrea, Marco \& Michele (2016) defined big data as the information assets characterized by such a high volume, velocity and variety to require specific technology and analytical methods for its transformation into value. Furthermore Fox (2018) has stated big data is 
where parallel computing tools are needed to handle data and notes. Big data allows data to be analyzed, extracted, stored, searched, shared, transferred, updated and etc. By using the previous data, analysis can be done to make a better decision making especially in the business transformation. As stated by Danah \& Kate (2011), analysis of data sets can find new correlations to spot business trends, prevent diseases, combat crime and many more.

System development is also a vital aspect for BPR specialist, as it an important driving force for planning, designing, executing and controlling activities that change the current process to new process in order to fullfil the today's business. The redesign of business process will decide the requirement systems of a software and inevitably affect the way of currently business. IT and BPR have recursive relationship as the IT capabilities should support business processes and business processes should be implemented in terms of capabilities IT can provide. The most important factors that contribute to the BPR's success is the effectiveness alignment of IT infrastructure. Obviously, IT has become a broad subject in today's era. Staff who have skill and knowledge in IT become a greatest resource in organizations as they competent to use IT to meet the organization's need. Therefore, it is recommended for undergraduate and postgraduate programme especially in management area to include IT courses as one of the main subjects in their syllabus. The programme should provide graduates from a wide variety of backgrounds with the necessary tools and skills for understanding complex IT problems and also knowing about the needs and requirements of a modern organization.

Sungau et al. (2013) echo such contention by stating that in any organization the business process has three main elements, namely input (data, customer requests, and tools), process (the phase in which customers or tools will go through several activities involving time and money), and output (the expected outcomes).To meet all requests made by the customers, organizations must therefore possess the best business process. In line with the fast-moving time, information technology has been rightfully positioned as the main enabler to complete the organisational needs in the new millennium. This is to be expected as business transactions have to be performed fast without comprising their quality.

Gathari and Shamsi (2014) agree in response to the changing business environment, many companies consider planning and investing in BPR. BPR uses redesign of business processes to achieve dramatic changes, such as increased profitability and productivity and to improve organizational performance. If they apply reengineering in their processes efficiently, the creativity and innovation will certainly expand. In such a case, BPR seems the most appropriate methodology to be used given its proven high efficiency and effectiveness. Amin et al. (2016) asserts (BPR) is a method for the analysis of enterprise processes with a process-oriented approach, illustrating relations between activities and processes, estimating cost, time, and resources of the changed processes and then improving and optimizing the processes. BPR is a phenomenon in which, through radical process redesign, some companies have boosted large-scale improvements in their vital business performances. So, it is a guarantee for risks controlling and implementation regarding deploying enterprise systems such as enterprise resource planning (ERP). In line with Amin et a. (2016), Aldakhil (2016) added that BPR is no more an innovative technique and many organizations including service sectors are using this as a technique in their originations. In addition, Enterprise Resources Planning is a complex piece of software and the contemporary organizations are using this as a source in order to implement the BPR. 


\section{CONCLUSION}

Clearly, previous studies have shown that current business processes are heavily influenced by earlier processes. Of course, the former are more efficient and effective than the latter as more insights are gained with the passing of time. Notably, organisations are now focussing on efforts to examine several methodologies in terms of their utility, strengths, weaknesses, and practicality. More importantly, selecting the best methodology has to be guided by focusing on existing process that may need continuous, incremental improvement that is manageable in terms of cost and implementation. In this respect, the research findings of this study indicate that BPR is the best methodology there is that can be applied to many business organizations.

\section{REFERENCES}

Aldakhil, A.M. (2016). Implementation of Business Process Re-Engineering in the Service Sector. International Journal of Business and Management. 11(2).

Amin, H., Majid, G., \& Farzad, S. (2016). Fuzzy model on selecting processes in Business Process Reengineering. Business Process Management Journal. 22(6), 1118-1138. https://doi.org/10.1108/BPMJ-05-2015-0057

Andrea, D.M., Marco, G., \& Michele, G. (2016). A formal definition of Big Data based on its essential features. Library Review. 65(3), 122-135. https://doi.org/10.1108/LR-06-2015-0061

Aquila, M.D. (2017). Factors Contributing to Business Process Reengineering Implementation Success. Walden University.

Aslam Mei Nur Widigdo, Marimin, Idqan Fahmi, \& Irfan Syauqi Beik. (2016). Business process improvement of funding: a proposition to increase the performance of Indonesian Islamic banking. Journal of Islamic Finance. 5(2), 66-79.

Aslina Saad. (2005). A New Paradigm in School Management: (BPR) Business Process Reengineering. University Pendidikan Sultan Idris.

Bahramnejad, P., Sharafi, S.M., \& Nabiollahi, A. (2015). A Method for Business Process Reengineering Based on Enterprise Ontology. International Journal of Software Engineering \& Applications (IJSEA). 6(1), 25-39.

Bhaskar, H.L. (2018). Business Process Reengineering: A Process Based Management Tool. Serbian Journal of Management. 13(1), 63-87.

Boyd, D. \& Crawford, K. (2011). Six Provocations for Big Data. Social Science Research Network: A Decade in Internet Time. Symposium on the Dynamics of the Internet and Society. https:doi:10.2139/ssrn.1926431

Dragan, J. \& Toni, M. (2016). Information Technology as Enabler for Business Process Reengineering - A Successful Case Study. In proceedings of the 13th International Conference on Informatics and Information Technologies. Macedonia.

Fox (2018). Data Science for Transport. Springer Textbooks in Earth Sciences, Geography and Environment. https://doi.org/10.1007/978-3-319-72953-4_1

Gershon, M. (2010) Choosing Which Process Improvement Methodology to Implement. Journal of Applied Business \& Economics. 10(5), 61.

Ghatari, A.R., \& Shamsi, Z. (2014). Business Process Reengineering in Public Sector: Ranking the Implementation Barriers. International Journal of Process Management and Benchmarking. https:doi: 10.1504/IJPMB.2014.063239

Goksoy, A., Ozsoy, B., \& Vayvay, O. (2012). Business Process Reengineering: Strategic Tool for Managing Organizational Change an Application in a Multinational Company. International Journal of Business and Management. 7(2), 89-112.

Habib, M.N. \& Shah, A. (2013). Business Process Reengineering: Literature Review of Approaches and Applications. In proceedings of the 3rd Asia-Pacific Business Research Conference, 1-8.

Hagg, H.W., Suskovich, D., Workman, G.W., Jamie, et al., (2007). Adaptation of Lean Methodologies for Healthcare Applications. RCHE Publications. Paper 24. Retrieved from http://Docs.Lib.Purdue.Edu/Rche_Rp/24

Hammer, M.J. \& Champy, J. (2000). Reengineering the corporation: a manifesto for business revolution. Summaries.Com

Hanafizadeh, P. \& Ossouli, E. (2011). Prosess Selection in Re-engineering by measuring degree of change. Business Process Management. 17(2), 284-310.

Hong, S-G., Siau, K., \& Kim, J-W. (2016) The impact of ISP, BPR, and customization on ERP performance in manufacturing SMEs of Korea. Asia Pacific Journal of Innovation and Entrepreneurship. 10 (1), 39-54. https://doi.org/10.1108/APJIE12-2016-008

Islam, S. \& Ahmed, M.D. (2012). Business process improvement of credit card department: a case study of multinational bank. Business Process Management Journal. 18(2), 284-303.

Khodambashi, S. (2013). Business Process Reengineering in Application Healthcare in a relation to Health Information System. 
Journal of International Conference on Health \& Social Care Information Systems \& Technologies. 9, 949-957.

Kumar, A. \& Ozdamar, L. (2004). Business Process Reengineering at the Hospitals: A case study at Singapore. In proceeding of the 18th European Simulation Multiconference. ISBN 3-936150-36-2

Lawal, A.K., Rotter,T., Kinsman, L., Nazmi Sari, Harrison, L., Jefferey, C., et al., (2014). Lean Management in health care: definition, concepts, methodology and effect reported (systematic protocol review). Systematic Reviews. 3.103.10.1186/2046-4053-3-103.

Liem, J. (2005). A comparison of BPR methodologies Using the NIMSAD Framework. Erasmus University Rotterdam.

Milan, R., et al. (2014). Implementation of Business Process Reengineering in Human Resource Management. University of Business Academy.

Mohamed Anwar Mohamed Jamil, Nur Ain Muin \& Zakaria Mustaffa. (2013). Adaptasi Sistem Kaizen Dalam Konsep Pengurusan Kendiri: Satu Kajian Kes Di Jabatan Pengajian Asia Timur, Universiti Malaya. ICSSR e-Journal of the Social Science Research. 1(1). e-ISSN: 22894977

Muhammad Aizat Md Sin \& Mohd. Rizal Razalli (2015). The Influence of It Infrastructure in Business Process Reengineering Project Performance In Islamic Banking. Jurnal Teknologi. 77(4), 97-103.

Natasha L.R (2003). Examining the Relationship Between Business Process Reengineering And Information Technology. Bowie State University Maryland, Europe.

Norlena Hasnan, Kabiru Jinjiri Ringim \& Mohd Rizal Razalli. (2017). Information technology (IT) capability and business process reengineering (BPR) implementation: evidence from Malaysian Islamic banks. International Journal of Business and Management. 1(2), 70-77.

Pande, P.S., \& Holpp, L. (2002). What is SIX SIGMA?. United States: Mc. Graw Hill.

Pande, P.S., Neuman, R.P., \& Cavanagh, R.R. (2000). The Six Sigma Way. How GE, Motorola, and Other Top Companies Are Honing Their Performance. United States: Mc. Graw Hill.

Puneet Sharma et al., (2015). Process Improvement by Implementation Of Kaizen As A Quality Tool Within Defined Constraints: A Case Study In Manufacturing Industry. International Journal of Science and Technology.1(1), 182-194.

Puvanasvaran, A.P., Robert, S.T., Kerk, \& Ismail., A.R. (2010). A Case Study of Kaizen Implementation in SMI. National Conference in Mechanical Engineering Research and Postgraduate Studies, University Malaysia Pahang. 374-392

Rémy, M.W. (2011). Getting ready for kaizen: organizational and knowledge management enablers, VINE. 41(4), 428-448 https://doi.org/10.1108/03055721111188520

Retrieved from https://sohailumar.files.wordpress.com/2014/03/reengineering_the_corporation-clean.pdf

Solaimurugan, A. (2011). A Case Study Of E-Supply Chain \& Business Process Reengineering of a Semiconductor Company in Malaysia. Universiti Sains Malaysia.

Sturdy, G.R. (2010). Business Process Reengineering: Strategies for Occupational Health and Safety. Cambridge Scholars Publishing. United Kingdom.

Sudhakar, G.P. (2010). The role of IT in Business Process Reengineering. Economica. 6(4), 28-35.

Sungau, J., Ndunguru, P.C., \& Kimeme, J. (2013). Business Process Reengineering: The Technique to Improve Delivery Speed of Services Industry in Tanzania. Independent Journal of Management and Production (IJM\&P). 4(1), 208-227. 